\title{
Effects of Air Temperature on COVID-19 Case Fatality Rate
}

Anna Sączewska-Piotrowska', Damian Piotrowski²

ABSTRACT

KEY WORDS: $\quad$ Case fatality rate; COVID-19; meta-analysis; survival analysis; air temperature.

JEL Classification: C41, J19, J10.

'Department of Labour Market Forecasting and Analysis, University of Economics in Katowice, Poland

2Department of Infectious Diseases and Hepatology, Medical University of Silesia, Poland

\section{Introduction and Literature Review}

The effects of global pandemics are visible in all areas of life. The more dangerous a pandemic, the greater the proportion of diagnosed people can die, or in other words, case fatality rate (CFR) is higher. Ferguson et al. (2020) emphasize that COVID-19 is the most serious respiratory virus since the H1N1 influenza pandemic of 1918. On June 24th, 2020 there were 9,129,156 total cases and 473,797 total deaths from COVID-19 (World Health Organization, 2020). By performing a simple calculation, CFR would amount to $5.19 \%$. However, this result should be treated with caution, as the COVID-19 pandemic is still ongoing. Therefore, the final CFR,

Correspondence concerning this article should be addressed to: Anna Sączewska-Piotrowska, Department of Labour Market Forecasting and Analysis, University of Economics in Katowice, Poland. E-mail: anna.saczewska-piotrowska@ue.katowice.pl after the pandemic's end, will differ. The CFRs of different epidemics and pandemics vary. For example, the CFR of the seasonal flu is about $0.1 \%$, the Spanish Flu 2.5\%, SARS between $9 \%$ and 11\%, MERS $34.4 \%$, Ebola (depending on the epidemc) up to $90 \%$ (Kadanali \& Karagoz, 2015; Petrosillo et al., 2020; Shabir, 2020). The most concerning situation arises when the CFR is high and the epidemic is spread across a large region.

The pandemic of coronavirus disease 2019 (COVID-19) began in December 2019 in Wuhan, China. The CFR of COVID-19 is only an estimate, because the pandemic is not over yet and new cases are occurring all over the world. For most people, the disease is asymptomatic, but for some groups of people, especially the elderly and/or those with comorbidities, it can be fatal. The CFR of the ongoing COVID-19 has been documented in a large number of studies: 
cross-country comparisons of the CFR (Khafaie \& Rahim, 2020), analyses of the impact of government health policy to the CFR (Sherpa, 2020), studies focusing on indicating age groups with the highest value of the CFR (Petersen et al., 2020; Verity et al., 2020), analyses of the relationship between the CFR and presence of comorbidities (Guan et al., 2020; Yang et al., 2020). The aforementioned studies were carried out at a macro and micro level - from region and country levels to the patient level. COVID-19 is a new disease and to understand and overcome it is in the interest of the whole world. It is crucial to prevent the economic crisis from spreading. The economic impact of COVID-19 is enormous, and numerous studies were already devoted to this issue (Atkeson 2020; Fernandes 2020; McKibbin \& Fernando, 2020; Nicola et al., 2020; Odhiambo, Weke \& Ngare, 2020; Sumner et al., 2020). Until a vaccine or an effective cure are created, limitation of economic activities in the form of lockdowns and social isolation are probably the only solutions that can prevent the spread of COVID-19. The effects of the further waves of the ongoing pandemic are unknown. Therefore, the distant consequences for the economy also remain unknown. The main concerns related to pandemic are associated with the severe course of the disease and high CFR. This situation will necessitate further lockdowns which will worsen the economic situation. The identification of the factors that affect the severe course and high CFR of COVID-19 seems to be one of the key issues. Factors which determine the variability of the CFR of COVID-19 include weather conditions such as air temperature or humidity.

The idea of ambient temperature related to viral infection is not new. It has been noted that viral acute respiratory tract infections (vARIs) occur more often in winter than in summer. The authors realize that vARIs are not a uniform group. The viruses that can cause vARIs include many unrelated families including adenoviruses, coronaviruses, respiratory syncytial virus (RSV), influenza, measles, mumps, parainfluenza viruses, hand-foot-andmouth (HFMD) viruses, rhinoviruses, rubella virus. Although the viruses differ in their physical form (the presence or lack of the lipid envelope, DNA or RNA as a genetic material, icosahedral, spherical, or filamentous shape), they share the same seasonality in temperature regions (Stewart, 2016). For example, in northern Europe, low temperature and low ultraviolet indexes were correlated with peaks of influenza virus activity during 2010-2018 (Ianevski et al., 2019). Upon closer look, the SARS-CoV-2 is not the first, but the seventh coronavirus that crossed the genetic barrier and gained the ability to infect humans (Zhu et al., 2020). Based on available sources, the past six coronaviruses followed the seasonality and caused most infections in the colder months (December to February in the Northern Hemisphere) (Mania et al., 2020). A sharp change of ambient temperature was associated with an increased risk of SARS infection (Tan et al., 2005; WHO, 2020). The ongoing epidemy caused by the seventh coronavirus began in December 2019 (Zhu et al., 2020) in patients hospitalized in several local health facilities. The patients were epidemiologically linked to a seafood and wet animal wholesale market in Wuhan, Hubei Province, China (Zhu et al., 2020; Wuhan Municipal Health Commission, 2019) and spread rapidly across the countries (Li et al., 2020). The beginning of the epidemy was in December which is the typical time of the year in northern hemisphere for increase of coronaviruses incidence (Stewart, 2016), hence the study of the temperature influence on the course of the epidemic seems to be rational.

The aim of this study was to determine the relationship between temperature and the CFR of the COVID-19. The results may aid to forecast the values of the CFR in the next waves of the COVID-19 and answer the question how fast the highest value of the CFR may occur in different countries. This knowledge allows to take appropriate actions by the governments, including preparation of adequate amount of personal protective equipment for healthcare professionals, preparation of places in hospitals for potential severe patients, and introduction of restrictions on the economic activities.

\section{Methods}

\subsection{Data}

The data regarding cases and deaths originate from official daily reports about COVID-19 from the World Health Organization (2020). The temperature data 


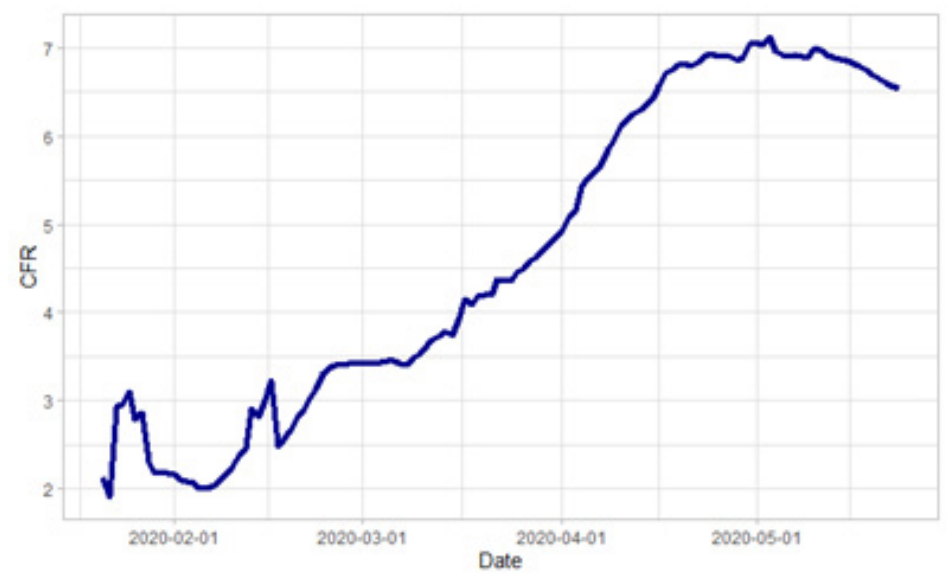

Figure 1. The CFR of the COVID-19 from the beginning of the pandemic to May 23, 2020.

was estimated by averaging air temperature in capital of each country in April ("List of cities by average temperature," 2020)

The first data about COVID-19 cases in database of the World Health Organization (WHO) appeared on January 21st, 2020. The analysis covers the period to May 23rd, 2020 when there were 5,103,006 total cases and 333,401 total deaths. Based on this data, the simply calculated CFR was $6.53 \%$. After conducting the analysis, on June 24th, 2020, as was mentioned in the Introduction, the CFR of the COVID-19 was $5.19 \%$ which means a further decrease in the CFR. The visualization of the CFR from January 21st to 23rd May, 2020 is in the Figure 1.

217 countries and territories were identified (after excluding the Diamond Princess cruise ship) according to the WHO database (data as of 10 a.m. CEST, May 23rd, 2020). In the analysis, the countries and territories with at least 10,000 total cases of COVID-19 on May 23rd, 2020 were included. 47 countries/territories met the selection criterium and were included in a meta-analysis (Figure 2). The term country will be used instead of counter/territory in the rest of the study.
In some cases (e.g. Panama, United States - US) the peak of the CFR of COVID-19 was visible in the beginning of the pandemic in certain country (when the number of cases was very low and even one death caused rapid increase in the CFR). In these cases, we decided to focus on the second peak of the CFR.

\subsection{Statistical Analysis}

A meta-analysis of prevalence data was carried out, with pooled estimates and 95\% confidence intervals. Due to expected variation between studies, substantial heterogeneity was expected, therefore a random-effects meta-analysis was performed. In the calculation process inverse variance method was used (Borenstein et al., 2010). The DerSimonianLaird estimator was implemented, which allows to calculate the between-study variance using the tau value (DerSimonian \& Laird, 1986). Betweenstudy heterogeneity was assessed using Higgin's $I^{2}$ and Cochran's $Q$ method. $I^{2}$ values of $25 \%, 50 \%$, and $75 \%$ were considered low, moderate and high heterogeneity, respectively (Higgins \& Thompson, 2002). A subgroup analysis was conducted by average temperature in April. To conduct the meta-analysis 


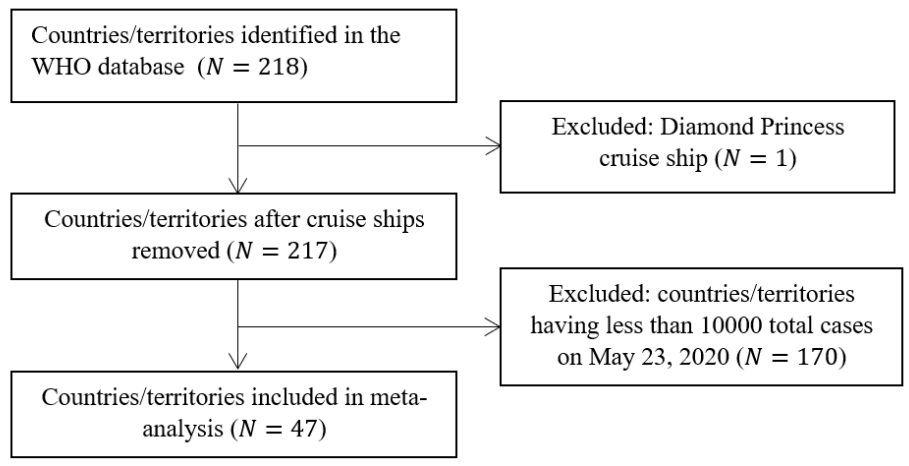

Figure 2. Flow-chart of country/territory selection.

in subgroups the cut-off points based on the median and the Youden index were determined. The CFR was dichotomized based on the median and then average temperature in April based on the Youden index (Heavner et al., 2010). Based on dichotomized values of the temperature the meta-analysis in subgroups was conducted. The results of the subgroup metaanalysis were presented using forest plots.

Survival analyses were performed using the Kaplan-Meier method (Kaplan \& Meier, 1958), and the log-rank test was applied to determine the influence of temperature on the pandemic duration to the maximum value. The Cox proportional hazards models were used to analyze the relationship between temperature and pandemic duration to the maximum value of the CFR. The proportional hazards assumption was tested by using scaled Schoenfeld residuals (Mills, 2011).

All analyses were performed with $\mathrm{R}$ software. The meta-analysis was carried out using meta package. Survival analysis was performed with survival and survminer packages. To determine the cut-off based on Youden index, OptimalCutpoints package was used.
In all analyses a $p$ value of less than 0.05 was considered statistically significant.

\section{Results}

\subsection{Subgroup Meta-analysis of the Peak of the CFR}

The meta-analysis showed that the pooled peak of the CFR was $4.63 \%(95 \% \mathrm{CI}=3.85 \%-5.55 \%)$ The betweenstudy variability was high $\left(\tau^{2}=0.4308\right.$, heterogeneity $I^{2}=100 \%$ with Cochran's statistics $Q=85546.14$, degrees of freedom $\mathrm{df}=46$ and $p$ value $=0$ ). The choice of the random-effect model at the beginning of the meta-analysis seems to be even more justified. Individual country CFR peak estimates ranged from $0.32 \%$ to $20.04 \%$. Subgroup analyses of the peak of the CFR were done for the air temperature (lower or equal to $14.8^{\circ} \mathrm{C}$, greater than $14.8^{\circ} \mathrm{C}$ ). The results are shown in Figure 3.

The pooled CFR peak was $6.12 \%(95 \% \mathrm{CI}=$ $4.81 \%-7.77 \%)$ for countries with temperature lower or equal to $14.8^{\circ} \mathrm{C}, 3.27 \%$ (95\% CI $=2.41 \%$ - $4.42 \%)$ for countries with temperature greater than $14.8^{\circ} \mathrm{C}$. Substantial heterogeneity $\left(I^{2}=100 \%\right)$ was observed in the both analyses. Individual CFR peak in countries with temperature $\leq 14.8^{\circ} \mathrm{C}$ ranged 


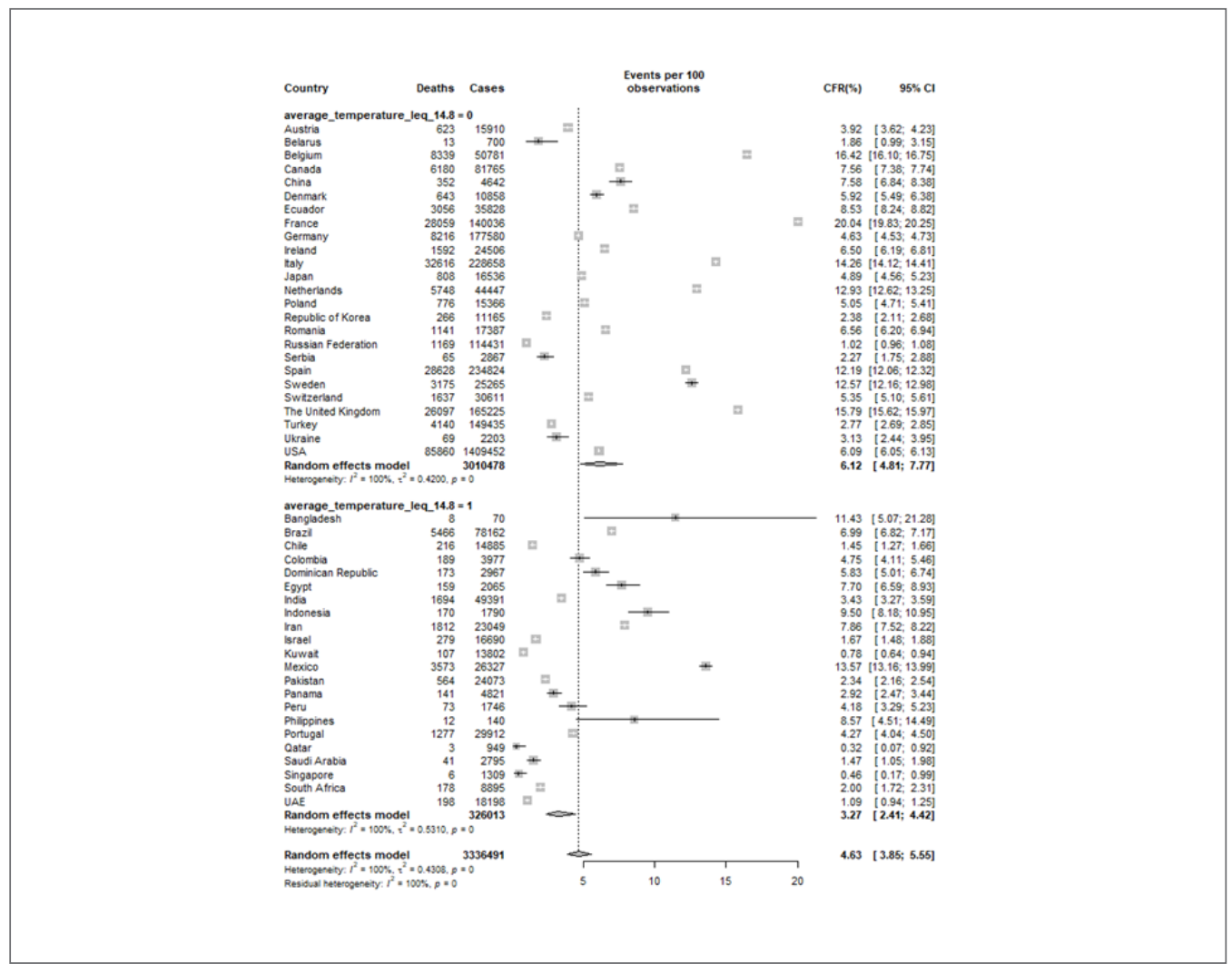

Figure 3. Forest plot of the subgroup analysis by air temperature at the moment of the CFR peak in individual country.

from $1.02 \%$ to $20.04 \%$, in countries with temperature $>14.8^{\circ} \mathrm{C}$ from $0.32 \%$ to $13.57 \%$.

The analogous calculations were made for the last day of the analysis, namely, May 23rd, 2020, when the most countries were after the peak of the CFR. The results are presented in Figure 4.

As of May 23rd, the pooled CFR was 3.45\% (95\% $\mathrm{CI}=2.84 \%-4.18 \%)$ The between-study variability was high $\left(\tau^{2}=0.4884\right.$, heterogeneity $I^{2}=100 \%$ with Cochran's statistics $Q=124894,64$, degrees of freedom $\mathrm{df}=46$ and $p$ value $=0$ ). Individual country CFR peak estimates ranged from $0.08 \%$ to $19.89 \%$. For countries with temperature $\leq 14.8^{\circ} \mathrm{C}$ the pooled CFR was $5.60 \%$ (95\% CI $=4.34 \%-7.19 \%$ ), and for countries with temperature $>14.8^{\circ} \mathrm{C}$ was $1.96 \%$ $(95 \% \mathrm{CI}=1.50 \%-2.57 \%)$. High heterogeneity $\left(I^{2}=100 \%\right)$ was observed in the both analyses. Indi- vidual CFR in countries with temperature $\leq 14.8^{\circ} \mathrm{C}$ ranged from $0.55 \%$ to $19.89 \%$, in countries with temperature $>14.8^{\circ} \mathrm{C}$ from $0.08 \%$ to $10.93 \%$.

\subsection{Pandemic duration to the CFR peak}

Not only the CFR differ across countries, also the time needed to reach the maximum value of the CFR in the first wave of the pandemic may be different. In this study the time (measured in days) needed to reach the maximum value of CFR is called as the "pandemic duration to the CFR peak". Analyzing the data from the first case of COVID-19 in each country to May 23rd, 2020, a majority of countries have reached the peak of the CFR. In the survival analysis there was assumed that there is no peak, that is, no event, when the CFR is still increasing. As of May 23rd, eight countries have not reached the peak of the CFR: Canada, Ecuador, 
Germany, Italy, Japan, Republic of Korea, and Spain. It should be emphasized that all these countries are from the group with average air temperature in April lower than or equal to $14.8^{\circ} \mathrm{C}$.

The survival analysis was started from the calculation of Kaplan-Meier estimates for all 47 countries (Figure 5). The median survival was 81 days, which means that $50 \%$ of countries reach the CFR peak after 81 or more days. Based on the Kaplan-Meier estimates is also visible that the overall survival rates at 50, 75, 100 days were $72.3 \%, 53.2 \%, 21.2 \%$, respectively. So it can be said that every fifth country will survive out of the CFR peak 100 or more days.

The comparison of the Kaplan-Meier estimates was also made (Figure 6). For the countries with average temperature lower or equal to $14.8^{\circ} \mathrm{C}$, the estimated median survival was 90 days, and for countries with temperature greater than $14.8^{\circ} \mathrm{C}$ was 58.5 days. The analysis showed that the survival rates at 50, 75, 100 days were $88 \%, 80 \%, 36.1 \%$ in countries with lower temperatures, and $54.6 \%, 22.7 \%, 4.6 \%$ in countries with higher temperatures, respectively. The KaplanMeier survival analysis successfully demonstrated that the survival rate of the CFR to the peak in the group of countries with average temperature lower or equal to 14.8 was significantly greater than that of the temperature greater than 14.8 (log-rank $\left.\chi^{2}=17.6, p<0.0001\right)$.

Two simple Cox proportional hazards models with different coding of the variable temperature were estimated. In Model 1 the temperature is a binary variable: lower or equal to $14.8^{\circ} \mathrm{C}$ and greater than $14.8^{\circ} \mathrm{C}$. In Model 2 the temperature is continuous variable. These proportional hazards models were estimated, because the assumption of proportional hazards is supported for both versions of covariates temperature: binary $\left(\chi^{2}=0.385, p=0.535\right)$ and continuous $\left(\chi^{2}=0.916\right.$, $p=0.338$ ). Results of the Cox regression analysis are shown in the Table 1.

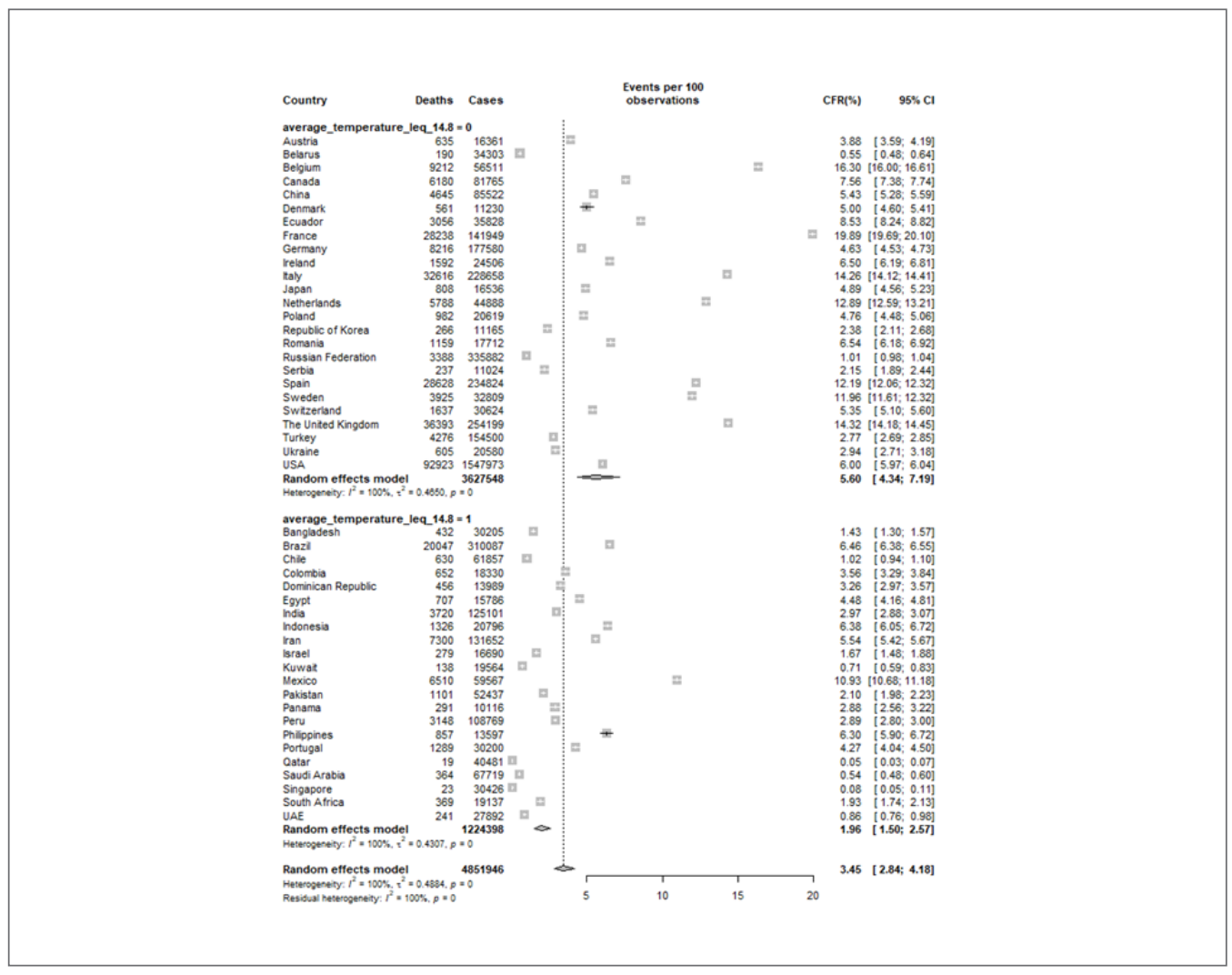

Figure 4. Forest plot of subgroup analysis by temperature on May 23, 2020. 


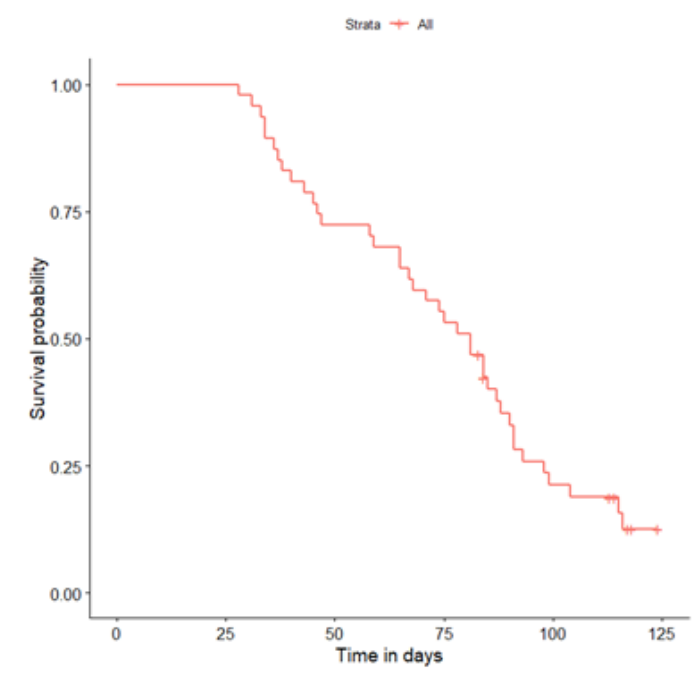

Figure 5. Kaplan-Meier survival curves.

In Model 1, the countries with temperature greater than $14.8^{\circ} \mathrm{C}$ had 3.95 times increased risk of reaching the CFR peak compared with countries with temperature lower or equal to $14.8^{\circ} \mathrm{C}$. Based on Model 2, it can be stated that for every one-degree increase in temperature, the risk of reaching the peak increases by an estimated $6.9 \%$.

\section{Discussion}

In past studies, the attention of researchers was paid to the relationship between the various diseases' prevalence and weather factors. We studied the association of, among others, air temperature, humidity, and cloud cover with the morbidity, mortality, and case fatality rates. Previous studies have focused not only on relationships between infectious diseases and the weather conditions but also on non-infectious diseases and the weather conditions. For example, Murphy et al. (2004) showed that there is substantial seasonal variation in atrial fibrillation hospitalizations and deaths.

Focusing on the influence of the weather conditions on the spread of previous epidemics/pandemics, it should be mentioned that studies regarding the relationship between meteorological factors and infectious diseases (such as avian influenza $\mathrm{A} / \mathrm{H}_{5} \mathrm{~N}_{1}$, SARS-CoV, and MERS-CoV) have been conducted. The first studies on COVID-19 and the weather conditions appeared. Lin et al. (2006) stated that in days with a lower air temperature during the epidemic, the risk of increased daily incidence of SARS-CoV (2003 epidemic) was 18 times higher than in days with a higher temperature (temperature higher than $24.6^{\circ} \mathrm{C}$ served as the reference level). The stability of the SARS coronavirus in different weather conditions was also analyzed by Chan et al. (2011). They showed that high temperature at high humidity has a synergistic effect on inactivation of SARS-CoV viability while lower temperatures and low humidity support prolonged survival of virus on contaminated surfaces. The environmental conditions of countries in tropical areas (e.g. Malaysia, Indonesia, Thailand) are thus not conducive to the prolonged survival of the virus.

Biswas et al. (2014) studied the meteorological factors (air temperature, relative humidity, cloud cover, rainfall, wind speed) in the occurrences of highly pathogenic avian influenza A/H5N1 in Bangladesh between 2007 and 2011. They stated that incorporation of one or any combination of the meteorological parameters as inputs in models did not improve the 


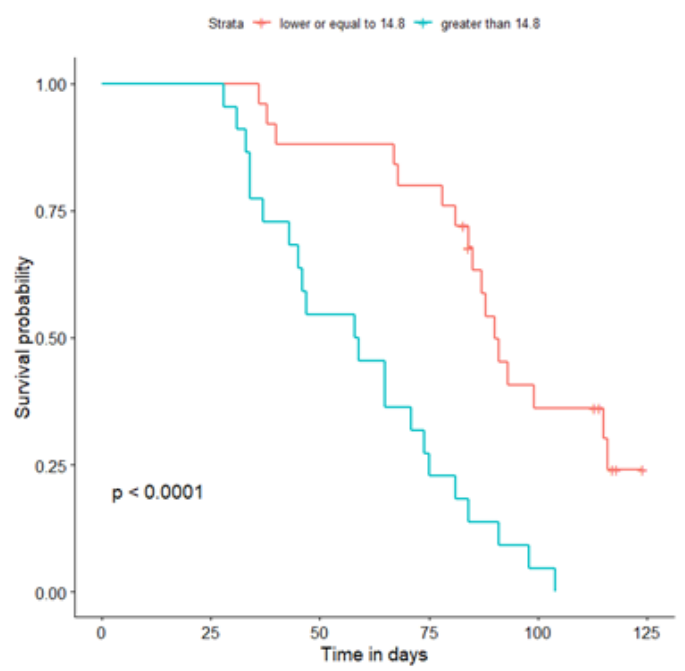

Figure 6. Kaplan-Meier survival curves according to the temperature.

performance of any model compared with the corresponding univariable model.

Doremalen and Munster (2013) showed that MERS$\mathrm{CoV}$ (epidemic in 2012) is characterized by the rapid decrease in virus viability at higher temperatures and higher humidity, which suggests that MERS-CoV and SARS-CoV share relatively similar stability characteristics.

Wu et al. (2020) based on data from 166 countries concluded that temperature was negatively related to the daily new cases and daily new deaths of COVID-19. Prata et al. (2020) found that the relationship between the annual average of temperature compensation and COVID-19 confirmed cases was approximately linear in the range of less than $25.8^{\circ} \mathrm{C}$, which became flat above $25.8^{\circ} \mathrm{C}$. When the average temperature was below $25.8^{\circ} \mathrm{C}$, each $1^{\circ} \mathrm{C}$ rise was associated with a $-4.8951 \%$ decrease in the number of daily cumulative confirmed cases of COVID-19. Shi et al. (2020) showed that in China the incidence of COVID-19 decreases with the increase of temperature. Wang et al. (2020) showed that the increased temperate and relative humidity significantly reduced the transmission of COVID-19 in 100 cities of China. Different results obtained authors from China (Luo et al., 2020; Yao et al., 2020), who stated that the increased temperature, humidity, and UV radiation did not reduce the incidence of COVID-19.

Our findings agree with the majority of the results showed in the previous studies. This study showed that the higher air temperature is associated with lower values of the CFR of COVID-19 and with shorter duration of pandemic to the CFR peak.

The methods used in this study were employed by researchers in few studies to analyze the pandemic of COVID-19. The meta-analysis was used by Oke and Heneghan (2020) to show the variation of the CFR in the countries with 1000 and more cases of virus. This analysis is still updating by the authors on the website (last update was June 9th, 2020). The pandemic of COVID-19 duration to the first peek of the mortality rate was studied by Jinjarak et al. (2020). The authors divided countries according to the time of the policy interventions. They concluded that in countries with early stricter policy interventions the pandemic duration to the first peak of the mortality rate is longer than in countries without such interventions.

\section{Limitations}

The main limitation of this study is that COVID-19 pandemic is still ongoing, therefore the calculations of 
Table 1. Cox models

\begin{tabular}{|c|c|c|c|c|}
\hline Variable & Coefficient & Exp (coefficient) & SE (coefficient) & $P$ value \\
\hline \multicolumn{5}{|c|}{ Model $1\left(\chi^{2}=15.89, p<0.0001\right)$} \\
\hline Temperature (ref. $\leq 14.8$ ) & 1.3747 & 3.9539 & 0.3473 & $<0.0001$ \\
\hline \multicolumn{5}{|c|}{ Model $2\left(\chi^{2}=9.04, p=0.003\right)$} \\
\hline Temperature (continuous) & 0.06685 & 1.06914 & 0.02169 & 0.00205 \\
\hline
\end{tabular}

Note: ref. - reference

the CFR may be different than in reality. Another limitation is associated with air temperature. In the analysis, due to the lack of relevant data from 2020, there were used the data from the previous years. It means that in the case of large deviations of temperature in 2020 from the average values from previous years the cut-off temperature may be different. Additionally, the values of temperature included in the analysis were from capital cities of individual countries, which means that these values do not reflect the values of temperature from the whole countries. The last limitation is related to classification of the deaths from COVID-19 in individual countries. The causes of death are differently classified in individual countries and the comparisons between countries should be treated carefully.

\section{Conclusion}

The conducted research should be helpful to undertake future management practices against COVID-19. In the absence of effective medicine and vaccine against virus, understanding the conditions favorable for the virus's spread (including weather conditions) could be the most effective way to arrest the further spread of COVID-19. The results of this study should serve as a warning, especially for countries with lower values of air temperatures. There is no doubt that the next wave of the novel coronavirus will have a wider spread, as the disease is already prevalent throughout the world. In June 2020 the CFR has been decreasing, but the second and the next waves of the virus may cause the problems in health care efficiency, increase in deaths from COVID-19, and increase in the CFR of COVID-19. Another consequence entails the deterioration of economic stability throughout the world. Summarizing, uncovering the favorable conditions for the virus is crucial from the perspective of the entire population. Additionally, further research on different factors causing the virus's spread should be conducted.

\section{References}

Atkeson A. (2020). What will be the economic impact of COVID-19 in the US? Rough estimates of disease scenarios (Working Paper No. 26867). National Bureau of Economic Research. https://doi.org/10.3386/ w26867

Biswas P. K., Islam M. Z., Debnath N. C., \& Yamage M. (2014). Modeling and roles of meteorological factors in outbreaks of highly pathogenic avian influenza H5N1. PLOS ONE, 9(6), 1-25. https://doi. org/10.1371/journal.pone.0098471

Borenstein, M., Hedges, L. V., Higgins, J. P., \& Rothstein, H. R. (2010). A basic introduction to fixed-effect and random-effects models for meta-analysis. Research synthesis methods, 1(2), 97-111. https://doi. org/10.1002/jrsm.12

Chan, K. H., Peiris, J. M., Lam, S. Y., Poon, L. L. M., Yuen, K. Y., \& Seto, W. H. (2011). The effects of temperature and relative humidity on the viability of the SARS coronavirus. Advances in Virology, 2011, 1-7. https://doi.org/10.1155/2011/734690

DerSimonian, R., \& Laird, N. (1986). Meta-analysis in clinical trials. Controlled Clinical Trials, 7(3), 177188. https://doi.org/10.1016/0197-2456(86)90046-2 
Ferguson N. M., Laydon D., Nedjati-Gilani G., ..., Ghani A. C. (2020). Impact of non-pharmaceutical interventions (NPIs) to reduce COVID-19 mortality and healthcare demand. Imperial College COVID-19 Response Team. https://doi.org/10.25561/77482

Fernandes N. (2020). Economic effects of coronavirus outbreak (COVID-19) on the world economy. SSRN Electronic Journal. https://doi.org/10.2139/ ssrn.3557504

Guan W. -J., Liang W. -H., Zhao Y., Liang H. -R., Chen Z. -S., Li Y. -M., ..., He J. -X. (2020). Comorbidity and its impact on 1590 patients with COVID-19 in China: a nationwide analysis. European Respiratory Journal, 55(5). https://doi. org/10.1183/13993003.00547-2020

Heavner, K. K., Phillips, C. V., Burstyn, I., \& Hare, W. (2010). Dichotomization: $2 \times 2(\times 2 \times 2 \times 2 \ldots)$ categories: infinite possibilities. BMC Medical Research Methodology, 10(1), 1-11. https://doi. org/10.1186/1471-2288-10-59

Higgins J. P. T., \& Thompson S. G. (2002). Quantifying heterogeneity in meta-analysis. Statistics in Medicine, 21(11), 1539-1558. https://doi.org/10.1002/ $\operatorname{sim} .1186$

Ianevski A., Zusinaite E., Shtaida N., Kallio-Kokko H., Valkonen M., Kantele A., ... Kainov D.E. (2019). Low temperature and low UV indexes correlated with peaks of influenza virus activity in Northern Europe during 2010-2018. Viruses, 11(3), 207. https://doi.org/10.3390/v1103020

Jinjarak, Y., Ahmed, R., Nair-Desai, S., Xin, W., \& Aizenman, J. (2020). Accounting for global COVID-19 diffusion patterns, January-April 2020. Economics of Disasters and Climate Change, 4(3), 515-559.

Kadanali A., \& Karagoz G. (2015). An overview of Ebola virus disease. Northern Clinics of Istanbul, 2(1), 81-86. https://doi.org/10.14744\%2Fnci.2015.97269

Kaplan E. L., \& Meier P. (1958). Nonparametric estimation from incomplete observations. Journal of the American Statistical Association, 53(282), 457-481. https://doi.org/10.1080/01621459.1958.10501452

Khafaie M. A., Rahim F. (2020). Cross-country comparison of case fatality rates of COVID-19/SARSCOV-2. Osong Public Health and Research Perspectives, 11(2), 74-80. https://doi.org/10.24171/j. phrp.2020.11.2.03

Li Q., Guan X., Wu P., Wang X., Zhou L., Tong Y., ..., Feng Z. (2020). Early transmission dynamics in Wuhan, China, of novel coronavirus-infected pneumonia. New England Journal of Medicine, 382(13), 1199-1207. https://doi.org/10.1056/NEJMoa2001316
Lin K., Fong D. Y. T., Zhu B., \& Karlberg J. (2006). Environmental factors on the SARS epidemic: Air temperature, passage of time and multiplicative effect of hospital infection. Epidemiology \& Infection, 134(2), 223-230. https://doi.org/10.1017/ S0950268805005054

List of cities by average temperature. (2020, May 20). In Wikipedia. https://en.wikipedia.org/wiki/List_ of_cities_by_average_temperature.

Luo W., Majumder M. S., Liu D., Poirier C., Mandl K. D., Lipsitch M., \& Santillana M. (2020). The role of absolute humidity on transmission rates of the COVID-19 outbreak. medRxiv.https://doi. org/10.1101/2020.02.12.20022467

Mania A., Kowala-Piaskowska A., \& Mozer-Lisewska I. (2020). Inne wirusowe zakażenia układu oddechowego (HRSV, HMPV, HADV) [Various viral respiratory infections (HRSV, HMPV, HADV)]. In R. Flisiak (Ed.), Choroby zakaźne i pasożytnicze (pp. 786-792). Czelej.

McKibbin W., \& Fernando R. (2020), The economic impact of COVID-19. In R. Baldwin, \& B. W. di Mauro (Eds.), Economics in the time of COVID-19 (pp. 45-51). Centre for Economic Policy Research.

Mills M. (2011). Introducing survival and event history analysis. Los Angeles-London-New Dehli-Singapore-Washington. Sage Publications.

Murphy N. F., Stewart S., MacIntyre K., Capewell S., \& McMurray J. J. V. (2004). Seasonal variation in morbidity and mortality related to atrial fibrillation. International Journal of Cardiology, 97(2), 283-288. https://doi.org/10.1016/j. ijcard.2004.03.041

Nicola M., Alsafi Z., Sohrabi C., ..., Agha R. (2020). The socio-economics implications of the coronavirus pandemic (COVID-19): A review. International Journal of Surgery, 78, 185-193. https://doi. org/10.1016/j.ijsu.2020.04.018

Odhiambo J., Weke P., \& Ngare P. (2020). Modeling Kenyan economic impact of coronavirus in Kenya using discrete-time Markov chains. Journal of Finance and Economics, 8(2), 80-85. https:// doi.org/10.12691/jfe-8-2-5

Oke J., \& Heneghan C. (2020). Global Covid-19 case fatality rates. March 17, 2020. https://www.cebm. net/covid-19/global-covid-19-case-fatality-rates/

Petersen E., Koopmans M., Go U., ..., Simonsen L. (2020). Comparing SARS-CoV-2 with SARS$\mathrm{CoV}$ and influenza pandemics. The Lancet Infectious Diseases, 20(9), e238-e244. , https://doi. org/10.1016/S1473-3099(20)30484-9 
Petrosillo N., Vieconte G., Ergonul O., Ippolito G., Petersen E. (2020). COVID-19, SARS and MERS: Are they closely related? Clinical Microbiology and Infection, 26(6), 729-734

Prata D. N., Rodrigues W., \& Bermejo P. H. (2020). Temperature significantly changes COVID-19 transmission in (sub)tropical cities of Brazil. Science of the Total Environment, 729. https://doi. org/10.1016/j.scitotenv.2020.138862

Shabir O. (2020, January 29). What is case fatality rate? News Medical https://www.news-medical.net/ health/What-is-Case-Fatality-Rate-(CFR).aspx

Sherpa D. (2020). Estimating impact of austerity policies in COVID-19 fatality rates: Examining the dynamics of economic policy and case fatality rates (CFR) of COVID-19 in OECD countries [Preprint]. medRxiv. https://doi. org/10.1101/2020.04.03.20047530

Shi P., Dong Y., Yan H., Zhao C., Li X., Liu W., ..., Xi S. (2020). Impact of temperature on the dynamics of the COVID-19 outbreak in China. Science of the Total Environment, 728. https://doi.org/10.1016/j. scitotenv.2020.138890

Stewart P.D.S. (2016). Seasonality and selective trends in viral acute respiratory tract infections. Medical Hypotheses, 86, 104-119. https://doi.org/10.1016/j. mehy.2015.11.005

Sumner A., Hoy C., \& Ortiz-Juarez E. (2020). Estimates of the impact of COVI-19 on global poverty (Working Paper 2020/43). United Nations University World Institute for Development Economics Research.. https://doi.org/10.35188/UNU-WIDER/2020/800-9

Tan J., Mu L., Huang J., Yu S., Chen B. Yin J. (2005). An initial investigation of the association between the SARS outbreak and weather: with the view of the environmental temperature and its variation. Journal of Epidemiology and Community Health, 59(3), 186-192. https://doi.org/10.1136/jech.2004.020180

Verity R., Okell L. C., Dorigatti I., Winskill P., Whittaker C., Imai N., ..., Ferguson N. M. (2020). Estimates of the severity of coronavirus disease 2019: A model-based analysis. Lancet Infectious Diseases, 20, 669-677. https://doi.org/10.1016/S14733099(20)30243-7

Wang J., Tang K., Feng K, \& Lv W. (2020). High temperature and high humidity reduce the transmission of COVID-19. https://doi.org/10.2139/ssrn.3551767

World Health Organization (2020). Coronavirus disease (COVID-2019) situation reports, https:// www.who.int/emergencies/diseases/novel-coronavirus-2019/situation-reports
Wuhan Municipal Health Commission (2019). Retrieved from http://wjw.wuhan.gov.cn/front/web/ showDetail/2019123108989

Wu Y., Jing W., Liu J., Ma Q., Yuan J., Wang Y., ..., Liu M. (2020). Effects of temperature and humidity on the daily new cases and new deaths of COVID-19 in 166 countries. Science of the Total Environment, 729. https://doi.org/10.1016/j.scitotenv.2020.139051

Yang J., Zheng Y., Gou X., Pu K., Chen Z., Guo Q., ..., Zhou Y. (2020). Prevalence of comorbidities and its effects in patients infected with SARS-CoV-2: A systematic review and meta-analysis. International Journal of Infectious Diseases, 94, 91-95. https://doi.org/10.1016/j.ijid.2020.03.017

Yao Y., Pan J., Liu Z., Meng X., Wang W., Kan H., Wang W. (2020). No association of COVID-19 transmission with temperature or UV radiation in Chinese cities. European Respiratory Society, 55. https://doi.org/10.1183/13993003.00517-2020

Zhu N., Zhang D., Wang W., Li X., Yang B., Song J., ... Tan W. (2020). A novel coronavirus from patients with pneumonia in China, 2019. The New England Journal of Medicine, 382(8), 727-733. https://doi.org/10.1056/NEJMoa2001017 